\title{
DA CRÍTICA HERMENEUTICA DO DIREITO DE LENIO STRECK AO JURISPRUDENCIALISMO DE CASTANHEIRA NEVES: UM CAMINHO PARA A SUPERAÇÃO DA DISCRICIONARIEDADE DO JUIZ NA ATUAL REALIDADE JURIDICA BRASILEIRA
}

\author{
Elias Kallás Filho ${ }^{1}$ \\ Tiago de Souza Fuzari ${ }^{2}$
}

\begin{abstract}
Resumo
Pretende o presente trabalho analisar a questão da discricionariedade do juiz, assim, volta-se para o contexto póspositivista, buscando o texto um diálogo entre a crítica hermenêutica do direito de Lenio Luiz Streck e o jurisprudencialismo de António Castanheira Neves, haja vista o fato de serem os autores afetos à base hermenêutica. Desse modo, traça-se um panorama acerca da questão da discricionariedade judicial no Brasil; valendo-se, para tanto, da teoria de Lenio Luiz Streck que alerta para o problema das recepções acríticas e descontextualizadas de teorias estrangeiras, as quais valorizam a aposta na figura do judiciário, bem como em sua subjetividade nas decisões de maior complexidade e relacionadas à implementação de direitos para as quais não se verificam ditames legais claros. Diante desse cenário e levando em conta a peculiar característica do jurisprudencialismo de associar hermenêutica e método, o que propicia maior aplicabilidade prática, vale-se o texto dessa teoria como um caminho para imprimir maior racionalidade prática ao ato decisório.
\end{abstract}

Palavras-chave: Discricionariedade Judicial; Jurisprudencialismo; Crítica Hermenêutica do Direito; Método; Racionalidade Decisória.

\section{INTRODUÇÃO}

Insere-se o texto em uma ambiência pós-positivista, na qual se voltam os olhos para a tentativa de emprego de uma racionalidade à atividade decisória com vistas ao afastamento da discricionariedade do julgador, sendo trazido, para tanto, elementos da crítica hermenêutica do direito de Lenio Luiz Streck e do jurisprudencialismo de António Castanheira Neves. Intenta-se, neste primeiro momento, realizar uma análise distintiva das teorias substancialistas e procedimentalistas, sendo tal distinção importante para se compreender a peculiaridade da concepção jurisprudencialista que, visando trazer maior operacionalização à hermenêutica,

\footnotetext{
${ }^{1}$ Pós-Doutor, Fundação São Francisco de Assis; Doutor em Direito Comercial, Universidade de São Paulo. Professor, Faculdade de Direito do Sul de Minas. Advogado. Pouso Alegre/MG - Brasil. E-mail: ekf@fdsm.edu.br

${ }^{2}$ Mestrando em Direito pela Faculdade de Direito do Sul de Minas - FDSM (2014 - 2016). Bolsista CAPES. Estagiário em Docência do PPGD/FDSM. Editor Associado da Revista da Faculdade de Direito do Sul de Minas. Graduado em Direito pela Faculdade de Direito do Sul de Minas - FDSM (2013).E-mail: tiagofuzari.adv@gmail.com
} vol.09, nº. 01, Rio de Janeiro, 2016.pp. 122-139 
realiza a sua associação com o método. A realização deste introito contextual mostra-se necessária, haja vista o objetivo futuro de se analisar a questão da discricionariedade do julgador na realidade brasileira pós 1988 e os possíveis contributos do jurisprudencialismo neste contexto.

Posteriormente, após delineado o sobredito panorama, adentra o texto na questão da discricionariedade do julgador, mas a partir de uma análise que leva em conta a ambiência brasileira, definindo, desse modo, quando tal questão passou a ganhar notoriedade e, eventualmente, ser vista como um problema, sendo a crítica hermenêutica do direito de Lenio Luiz Streck o ponto de partida. Assim, verifica-se que, no constitucionalismo do pós-guerra, viu-se uma sobrevalorização do Judiciário a partir dos novos compromissos nascidos, notadamente do âmbito da implementação de direitos. Tal questão chegou ao Brasil a partir da Constituição de 1988, tornando o cenário jurídico brasileiro um fértil campo para a recepção acrítica e descontextualizada de teorias estrangeiras que passaram a ser aplicadas de maneira desnaturada, gerando uma maior aposta na figura do Judiciário, o que acaba, por vezes, a colocar o ato decisório a mercê da subjetividade do julgador.

Por fim, estabelecido o panorama do ativismo judicial no Brasil, a partir dos ditos desafios do constitucionalismo contemporâneo de Lenio Luiz Streck, o texto deste se afasta, voltando-se à aplicabilidade prática trazida pelo jurisprudencialismo e a sua capacidade de associar hermenêutica e método. Assim, trabalha-se com questões afetas à forma de se lidar com a discricionariedade do juiz diante de lacunas ou situações de busca de implementação de direitos, a partir da ótica do jurisprudencialismo, trazendo-se à tona questões como a mediação, sistema e problema, condições de emergência do direito e o emprego da analogia. Tem-se por escopo, neste ponto, a busca da maior racionalidade e o controle necessários ao ato decisório, desviando-se, de maneira mais palpável, da subjetividade.

A pesquisa realizada foi eminentemente teórica, baseando-se em pesquisa bibliográfica, a qual foi utilizada como base para produção do trabalho, pautando-se por uma metodologia histórico-analítica.

\section{ENTRE O SUBSTANCIALISMO E O PROCEDIMENTALISMO: O CAMINHO APONTADO POR CASTANHEIRA NEVES}

A relação entre jurisdicionado e julgador atualmente se apresenta como uma relação muito mais fluida e simples do que a relação entre representado e representante no âmbito do Legislativo (OLIVEIRA, 2010, p. 137), não se podendo olvidar que, a despeito de todas as mazelas que afligem a Justiça brasileira, é muito mais fácil se obter uma audiência ou ter sua pretensão levada à apreciação do juiz do que se conseguir que o representante do Legislativo, ou mesmo do Executivo, aprecie a mesma demanda ou se posicione acerca de determinada questão.

Não se pretende com isso desprezar toda a complexidade existente por trás da representação indireta, tampouco as minúcias e o tempo de maturação necessários ao processo legislativo; nem se quer adentrar em 
discussões afetas à crise de representatividade ou aos problemas concernentes à representação indireta. Mas, para além dessas questões, há que se convir que, no âmbito do Judiciário, devido ao fato de lidar com o caso concreto, encontra-se o juiz em uma posição de vantagem em relação ao legislador, impondo-se a ele a função de lidar justamente com a transformação de uma pretensa vontade geral e abstrata da lei em vontade concreta.

Experimenta o juiz, portanto, os resultados do direito posto, vendo suas possíveis incongruências e seus problemas, a partir dos dramas reais que todos os dias adentram em seus gabinetes, tendo de sempre se manifestar por imposição legal (OLIVEIRA, 2010, p. 137). Mas, afastando qualquer tipo de análise idealizada e, por vezes, romantizada em torno da figura do julgador, em um sistema constitucional, democraticamente estabelecido, a última palavra é do legislador, sendo ele quem edita, revoga ou suplementa determinado entendimento, estando a jurisdição à sua vontade submetida.

No entanto, verifica-se uma frequente aposta na figura do julgador, fato este que, no contexto brasileiro pós 1988, tem-se traduzido em eventuais atitudes de imposição conteudística por parte do Judiciário (TASSINARI, 2013, p. 112), trazendo luz para discussões concernentes aos limites de atuação do juiz, até onde pode ele atuar com vistas à implementação de direitos e, primordialmente, como deve o julgador se portar diante de um caso mais complexo, situação essa que ficou conhecida como "casos difíceis" ${ }^{\prime \prime}$, em que se verifica uma maior abertura à escolha do juiz, abrindo-se caminho para a discricionariedade.

Com vistas a analisar esta situação, há que se voltar os olhos para o contexto pós-positivista e as teorias nele surgidas que, de maneira geral, construíram-se em torno da busca de alguma forma de superação da subjetividade do julgador, pondo-se em contraponto ao contexto neopositivista de Kelsen, em que se evidenciava, a partir das opções mostradas pelo direito - formando a moldura - uma escolha necessária do julgador que se dava, em última análise, em um ato subjetivo pautado por elementos de fora do direito. ${ }^{4}$

Nesse sentido, mostrou o neopositivismo que todo ato de decisão jurídica carrega certo tom de subjetividade, a qual é aceita com base na competência do órgão que proferiu a decisão, sendo justamente essa competência que dava à decisão o status de juridicamente correta. Essa situação pôs abaixo o ideal de uma resposta justa e correta, bem como mostrou a existência de um déficit de legitimidade (SIMIONI, 2014, p. 235).

\footnotetext{
${ }^{3}$ Explica Ronald Dworkin que, no âmbito do positivismo jurídico existe a chamada teoria dos casos difíceis, caracterizando-se tais casos, quando "[...] uma ação judicial específica não pode ser submetida a uma regra de direito clara, estabelecida de antemão [...]". Distintamente dos casos fáceis, em que a subsunção a norma ocorre de plano, nos casos difíceis "[...] o juiz tem, segundo tal teoria, o poder discricionário para decidir de uma maneira ou de outra.” (DWORKIN, 2007, p. 127).

${ }^{4}$ Acerca da questão, importante ressaltar que segundo o pensamento kelseniano: "O Direito [...] forma, em todas estas hipóteses, uma moldura dentro da qual existem várias possibilidades de aplicação[...]. Sendo assim, a interpretação de uma lei não deve necessariamente conduzir a uma única solução como sendo a única correta, mas possivelmente a várias soluções que - na medida em que apenas sejam aferidas pela lei a aplicar - têm igual valor, se bem que apenas uma delas se torne Direito positivo no ato do órgão aplicador do Direito - no ato do tribunal, especialmente. Dizer que uma sentença judicial é fundada na lei, não significa, na verdade, senão que ela se contém dentro da moldura ou quadro que a lei representa - não significa que ela é a norma individual, mas apenas que é uma das normas individuais que podem ser produzidas dentro da moldura da norma geral.” (KELSEN, 1999, p. 247). Será justamente sobre este processo de escolha das opções existentes na moldura que se debruçará o pós-positivismo.
} vol.09, nº. 01, Rio de Janeiro, 2016.pp. 122-139 
Justamente neste ponto, nascem os motes das correntes pós-positivistas, tentando estabelecer um meio racional para orientar essa escolha do julgador e retirar, desse modo, a subjetividade nela existente.

A tarefa de justificar racionalmente algo a que o neopositivismo deixava a cargo da subjetividade do julgador - ou, dito de outra forma, fora do âmbito jurídico, influenciando-se por questões como a moral, a política etc. - também se coloca como algo complexo, nascendo daí duas correntes teóricas distintas, quais sejam, o procedimentalismo e o substancialismo. A primeira teoria impõe o desenvolvimento de uma argumentação jurídica baseada em regras procedimentais, afastando-se, assim, o subjetivismo e garantindo-se o atingimento de um consenso racional; já a segunda, baseia-se na existência de princípios e valores substanciais que seriam capazes de orientar o decidir do julgador promovendo convicções que justificariam racionalmente a decisão (SIMIONI, 2014, p. 247).

Destaca-se, desse modo, como ponto comum, tanto entre os procedimentalistas, como entre os substancialistas, além da busca por prover racionalidade à decisão, o afastamento de quaisquer bases ou origens metafísicas ou jusnaturalistas como fundamento do exercício da jurisdição; calcando-se o substancialismo, como já delineado acima, pela existência de um vasto consenso material na sociedade, sendo princípios e valores os supedâneos racionais da decisão e, de outro lado, o procedimentalismo que, por não compartilhar a ideia de existência de tal acordo no âmbito social, aposta no estabelecimento e conhecimento de regras procedimentais como elemento para dar a buscada racionalidade ao ato decisório (OLIVEIRA, 2010, p. 152).

Tal contextualização mostra-se necessária, haja vista o intento do presente texto que, ao analisar a questão da discricionariedade judicial na realidade brasileira pós 1988, trará elementos concernentes à crítica hermenêutica do direito de Lenio Luiz Streck, bem como à concepção jurisprudencialista de António Castanheira Neves. Diante disso, importante entender como esses autores estão inseridos nesse contexto pós-positivista, bem como o seu alinhamento com as teorias procedimentalistas e substancialistas.

Lenio Streck (2011, p. XX) insere-se no campo do substancialismo e tem como matriz a hermenêutica filosófica ${ }^{5}$ que orientará a sua crítica hermenêutica do direito, sendo os limites da atuação jurisdicional tema de grande relevância em seu trabalho. Tem o autor, portanto, uma contribuição que transcende a mera análise desses limites, com uma proposta de reflexão muito mais abrangente, podendo ser sintetizada na busca pela ruptura com o dogmatismo por meio da afirmação de uma hermenêutica crítica na interpretação e aplicação do direito; na demonstração da existência de inter-relações entre o direito e a filosofia e, a partir de tudo isso, busca ele elaborar

\footnotetext{
${ }^{5}$ Importante salientar que, explica Rafael de Oliveira Costa que a Hermenêutica, em sua matriz heideggeriana-gadameriana, tem por grande característica a superação do paradigma sujeito-objeto. (COSTA, 2014, p. 124). Heidegger e Gadamer demonstraram que as condições de objetividade e a influência da subjetividade no processo hermenêutico põe-se no centro da virada ontológica da Hermenêutica, assim o processo de interpretação envolverá pressupostos e (pre) conceitos do intérprete, de modo que o interpretar nunca decorre de uma atitude que se aparta de uma visão prévia do intérprete. Destaca, contudo, que o processo hermenêutico não pode ser fruto de preferências pessoais do intérprete e mesmo não sendo o método o caminho único para a verdade, não pode o jurista ignorar busca pela previsibilidade e segurança na aplicação do Direito (COSTA, 2014, p. 124-126).
} vol.09, nº. 01, Rio de Janeiro, 2016.pp. 122-139 
uma teoria da decisão judicial, a qual se constrói a partir de imbricações da teoria de Ronald Dworkin (TASSINARI, 2013, p. 109).

A despeito da vastidão pela qual se pode enveredar nos pensamentos de Lenio Streck, cingir-se-á o texto à sua contribuição no que concerne à análise da situação da atividade jurisdicional, no âmbito brasileiro, após o advento do Estado democrático de direito, sendo suas críticas ponto de partida para o que se construirá à frente.

António Castanheira Neves, de maneira peculiar, transita entre o substancialismo e o procedimentalismo, conforme será mostrado adiante. Inicialmente, cumpre observar que ele se insere também no âmbito do pós-positivismo, construindo uma concepção jurisprudencialista do direito, na qual é o direito visto como uma realização prática, ou seja, uma experiência jurídica prática. Coloca a decisão jurídica no centro de sua problemática, além de realizar um resgate dos princípios axiológicos materiais no âmbito dos problemas práticos, afastando a ideia de se ver o direito como um instrumento do poder ou um meio para a consecução de finalidades, sendo, assim, uma questão de validade no âmbito de uma responsabilidade ética da comunidade (SIMIONI, 2014, p. 403).

Para além disso, o que importa, neste momento, é o fato de ter este autor realizado algo até então concebido como proibido, uma vez que juntou a hermenêutica filosófica e o método. Em sua construção, foi influenciado por Gadamer e Heidegger, no entanto, a hermenêutica não fora assumida de maneira passiva, sendo que sua postura crítica o fez entender que o jurista não pode ser apenas um filósofo, visto que é necessário que se tenha um método para se chegar a um resultado prático, pois, em sua visão, a hermenêutica propicia a compreensão, mas não realiza o direito, cumprindo a sua realização prática (interpretação e decisão) à metodologia (SIMIONI, 2014, p. 404).

No entanto, é a hermenêutica avessa ao método, inserindo-se ela na linha das teorias substancialistas; e a aplicação de método, na linha dos procedimentalistas. Assim realizou Castanheira Neves o trânsito entre essas duas teorias, sendo este seu elemento crucial para adoção neste texto. Entende ele que, na linha hermenêutica, consegue o jurista realizar significativas reflexões filosóficas, mas que não se operacionalizam, de modo a não traspassarem, no momento da decisão, o mundo das ideias. Isso faz com que o julgador fique impedido de lidar com a prática. Assim, como sua marcante característica, traz autor o método para a hermenêutica, mas sem sufocála, mantendo a sua criatividade e intuição.

Embora faça a ponte entre os dois mundos (hermenêutica e método), sua concepção enquadra-se em uma perspectiva pós-positivista de caráter substancial, ou seja, é ele um autor substancialista. A sua posição póspositivista jurisprudencialista afasta-se de perspectivas sociológicas funcionais, bem como do positivismo jurídico, pressupondo sua metodologia uma superação radical do estilo de interpretação e decisão jurídica positivista (SIMIONI, 2014, p. 405). 
Justamente pelo fato de Castanheira Neves mostrar-se como um contraponto à dualidade substancialismo e procedimentalismo, sendo ele um caminho de conciliação entre hermenêutica e método, intentará o presente trabalho, a partir da análise crítica acerca da atividade jurisdicional no contexto brasileiro trazida por Lenio Luiz Streck, mostrar como pode o jurisprudencialismo contribuir na atividade do julgador, notadamente, diante de questões para as quais a lei mostra-se lacunosa ou que exigem uma atuação mais incisiva do juiz, adentrando-se no ponto de fronteira entre a vontade do legislador e um ato de ativismo jurídico. A confrontação destes autores deu-se em decorrência do fato de partirem ambos da base hermenêutica e sendo eles autores substancialistas, com vistas a analisar o contributo da aplicabilidade prática trazida pelo jurisprudencialismo.

\section{O ATIVISMO JUDICIAL NO BRASIL PÓS 1988, UM PROBLEMA A PARTIR DA VISÃO DA CRÍTICA HERMENÊUTICA DO DIREITO}

Uma vez estabelecido este breve panorama acerca dos autores com os quais pretende o texto trabalhar, necessário que se adentre na questão da discricionariedade do julgador, mas a partir de uma análise que leve em conta a ambiência brasileira, definindo, desse modo, quando tal questão passou a ganhar notoriedade e, eventualmente, ser vista como um problema, além de se mostrar uma possível mácula à democracia, haja vista a invasão, por parte do Judiciário, em questões comumente afetas ao Legislativo. Para a exploração de tais questões, a crítica hermenêutica do direito de Lenio Luiz Streck funcionará como ponto de partida, haja vista sua peculiar leitura da realidade brasileira.

Contudo, antes de se adentrar na questão da discricionariedade, insistirá o texto na dicotomia entre as teorias substancialistas e procedimentalistas e, em uma espécie de antessala da abordagem pretendida no contexto da Constituição brasileira de 1988, cumpre explicitar como os diferentes tipos de constituição relacionam-se com as sobreditas teorias, aduzindo Fábio Correia de Oliveira (2010, p. 153) que os textos constitucionais desprovidos de grande carga de compromissos conteudísticos têm melhor relacionamento com as teorias de cunho procedimental, já as constituições que apresentam maior nível de compromissos, como é o caso brasileiro, espanhol e português, apresentam maior afinidade com teorias de cunho substancialista.

Adverte o sobredito autor, no entanto, que não se verificam óbices em se aplicar uma visão substancialista a uma constituição mais sintética. Como exemplo cita-se o que Ronald Dworkin faz no contexto estadunidense, mas o contrário traria significativos problemas para as constituições com grande carga compromissária, uma vez que uma visão procedimental imporia a exclusão de determinados postulados, o que poderia gerar a sua desubstancialização. Assim, a insistência deste texto em caminhar em uma linha afeta à hermenêutica mostra-se congruente com o contexto analisado. 
A questão da discricionariedade judicial começa a ganhar vulto, no caso brasileiro, após o advento do Estado democrático de direito com a Constituição de 1988. Tal documento insere-se no âmbito do pós-guerra, no qual se viu o nascimento de um novo constitucionalismo voltado à concretização de direitos fundamentais, à ruptura com o positivismo (pós-positivismo) e à exigência de uma nova teoria da constituição, surgindo, em relação a este último ponto, uma série de divergências entre os autores que se debruçaram sobre o tema. De qualquer forma, como vertente comum entre os múltiplos posicionamentos, verifica-se o resgate do papel dos princípios na interpretação jurídica, a reconciliação entre direito e moral e a afirmação de um protagonismo judicial, elemento focal do texto, tendo-se assistido a um aumento do papel da jurisdição e uma maior amplitude das faculdades interpretativas do julgador (TASSINARI, 2013, p. 110).

Nesse novo panorama erigido pelo constitucionalismo do pós-guerra, verificou-se, em decorrência das profundas mudanças ocorridas, a noção de que o Estado democrático de direito pressupõe uma valorização do Judiciário. Isso, aduz Lenio Luiz Streck (2015), impõe uma rediscussão acerca do papel do Judiciário e da justiça constitucional, o que é ainda mais urgente em países de "modernidade tardia" (MORAIS; STRECK, 2008, p. 84), pois o novo modelo constitucional tem não só que lidar com esses novos compromissos assumidos, mas tem também de suprir etapas anteriores, resgatando promessas da modernidade ainda não cumpridas, o que torna a atuação do Judiciário ainda mais proeminente.

Este novo panorama surgido nas constituições do pós-guerra, nominou Lenio Streck (2011, p. 16) Constitucionalismo Contemporâneo, com vistas a evitar eventuais mal-entendidos vinculados ao termo neoconstitucionalismo. Assim, no âmbito da crítica hermenêutica do direito e dando enfoque ao problema do ativismo do julgador, aponta ele alguns desafios que se colocam ao Constitucionalismo Contemporâneo, dentre os quais irá o texto se concentrar em dois deles, quais sejam, o enfrentamento das recepções acríticas e descontextualizadas de teorias estrangeiras e a necessidade de se superar a discricionariedade judicial.

A começar pela recepção acrítica e descontextualizada de teorias estrangeiras, verifica-se que o advento da Constituição de 1988 e as modificações trazidas por esse novo constitucionalismo que se desenhava tornaram o Brasil um campo fértil para a proliferação de posicionamentos derivados de outras culturas jurídicas, as quais foram assimiladas sem grande reflexão e aplicadas de modo descontextualizado, promovendo-se, inclusive, mixagens e releituras que trouxeram graves consequências no tocante à atividade jurisdicional e seus limites, situação esta de tamanha peculiaridade que Lênio Streck nominou ativismo judicial à brasileira (TASSINARI, 2013, p. 108 - 109).

Dentre essa multiplicidade teórica que aportou em terras brasileiras, três delas podem ser destacas por seu grande contributo na majoração de poderes do julgador. A primeira delas foi a teoria alemã da jurisprudência de valores, a qual deixou no Brasil a ideia de que a constituição deve ser concebida como ordem de valores e a 
atuação jurisdicional pode ser fundada em critérios que estão além dos parâmetros legais. Assim, diante da impossibilidade do juiz resolver o caso por meio da legislação, pode ele utilizar valores adicionais através de cláusulas indeterminadas e cláusulas gerais, situação esta que transforma o Judiciário em tutor político, superpoder e guardião da moral e dos bons costumes (TASSINARI, 2013, p. 112).

Em segundo lugar, viu-se a teoria da ponderação, de Robert Alexy, na qual os princípios ganham o status de mandados de otimização $0^{6}$ empregados como critérios interpretativos apenas na insuficiência da regra, abrindose, assim, espaço para a ponderação. O grande problema é que, no Brasil, a ponderação foi recepcionada como princípio, quando, na verdade, é uma regra. Desse modo, tornou-se a ponderação um simples sopesamento de princípios que é aplicado de maneira arbitrária e sem qualquer respeito às suas feições originais, evidenciando-se, assim, um claro efeito das mixagens e desnaturações ocorridas na absorção dessas teorias estrangeiras (TASSINARI, 2013, p. 114).

Por fim, destaca-se também a teoria estadunidense do governo dos juízes, que no Brasil, teve absorvido principalmente a ideia de que o ativismo judicial é bom para a democracia, quando direcionado para concretizar direitos. Isso trouxe resultados antagônicos, quais sejam, a ideia de aumento de atribuições do Judiciário, podendo ele se manifestar acerca de questões que antes estavam fora de sua esfera de atuação (ampliação de competências); constituindo-se, desse modo, o "bom ativismo", mais conhecido como judicialização das políticas públicas. E, do outro lado, a atividade jurisdicional progressista, caracterizada pela sua interferência política direta e imoderada, sendo este o ativismo judicial propriamente dito, em que se vê o avultamento do subjetivismo da discricionariedade do julgador (TASSINARI, 2013, p. 114).

O que se verifica em comum entre todas essas teorias, a partir dessas recepções incoerentes, conforme já aventado acima, é o seu contributo no protagonismo judicial, que acaba por levar o julgador a desvincular-se da lei, gera a abertura à subjetividade do interprete, além da interferência política por parte do Judiciário, de modo a macular a democracia. Diante disse cenário, passa a figurar a superação do sobredito quadro como um desafio a ser transpassado pelo Constitucionalismo Contemporâneo. Nesse sentido, pretende o texto uma aproximação ao jurisprudencialismo de Castanheira Neves, como forma de superar as mazelas carreadas por essas teorias incoerentemente adotadas, uma vez que propicia uma postura de maior racionalidade na atividade decisória, notadamente em decorrência de sua aproximação entre hermenêutica e método (SIMIONI, 2014, p. 403), que se evidencia notadamente quando colocado o julgador diante de questões para as quais se imporá uma eventual atividade criativa ou uma atuação para além da lei. Isso mostra-se ainda mais importante em países ditos de

\footnotetext{
${ }^{6}$ Robert Alexy, ao tratar da distinção entre regras e princípio no âmbito da norma, aduz serem os princípios mandamentos de otimização, de modo que se caracterizam por poderem ser satisfeitos em graus variantes, ou seja podem ser parcialmente satisfeitos e essa satisfação não depende apenas de possibilidades fáticas, mas também de possibilidades jurídicas. Já as regras operam sob uma sistemática diferenciada, uma vez que ou são satisfeitas ou não satisfeitas, não havendo, portanto, essa variação em graus (ALEXY, 2006, p. 90-91).
} 
modernidade tardia em que a busca pela efetivação de direitos constitucionalmente previstos acarreta eventuais invasões criativas do judiciário na esfera legislativa.

No que concerne, em específico, ao que Lenio Streck chama de desafio da superação da discricionariedade do juiz, não volta ele os olhos para a forma como determinadas teorias foram recepcionadas, mas para a teoria em si, estando o problema localizado em sua estruturação. Assim, aduz que significativa parte das teorias que se intitulam pós-positivistas ou neoconstitucionalistas parecem não ter compreendido muito bem o neopositivismo de Kelsen, não percebendo os dois níveis contidos em sua proposta, quais sejam, o da ciência e o da aplicação. Nesse sentido, quando Kelsen trata da interpretação, não se preocupa com uma teoria acerca de como se deve decidir corretamente, ou, dito de outro modo, não se preocupa em como se dará a escolha dentro da moldura (isso não compete ao direito), motivo pelo qual, no campo da aplicação, admite-se, a exemplo, a aplicação da moral. Conforme adiantado acima, isso parece não ter sido entendido por algumas teorias que, ao tentarem superar tal postura, parecem buscar superar o positivismo exegético e o fazem por meio da ampliação da discricionariedade (TASSINARI, 2013, p. 116).

Diante dessa situação, faz-se necessário perceber que a influência dessas teorias acaba por colocar o ato decisório completamente à mercê da subjetividade do intérprete, resumindo-o à vontade de quem julga, descambando-se, desse modo, para o ativismo judicial. Isso torna premente, como mais um desafio do Constitucionalismo Contemporâneo, a construção de um Judiciário no qual os poderes discricionários e/ou liberdades interpretativas sejam superadas (TASSINARI, 2013, p. 118). Diante disso, mais uma vez a aproximação ao jurisprudencialismo de Castanheira Neves faz-se viável, notadamente quando traz elementos como intenção normativa e intenção prática do problema associado à sua peculiar visão sobre a analogia.

\section{DIRETRIZES PARA A ATUAÇÃO DO JULGADOR E O CAMINHO APONTADO POR CASTANHEIRA NEVES}

Uma vez estabelecido o panorama acerca do ativismo judicial, a partir da visão da crítica hermenêutica do direito, valer-se-á o texto do jurisprudencialismo de António Castanheira Neves para trabalhar com a questão de como se deve lidar com a discricionariedade do juiz, o qual, por vezes, coloca-se diante de lacunas ou situações de busca de implementação de direitos, cujos cabrestos legais não são suficientes para conduzir a sua atividade decisória, a qual acaba por se efetivar sem uma prévia racionalidade ou um fio norteador que a oriente, concentrando-se apenas na convicção subjetiva do decisor.

Delineados os desafios pertinentes à questão, que se coloca no âmbito do Constitucionalismo Contemporâneo de Lenio Streck, o texto dele se afasta, haja vista a aplicabilidade prática trazida pelo jurisprudencialismo e a sua capacidade de associar hermenêutica e método, de modo a torná-la operacional para 
decisão jurídica, conferindo, assim, a racionalidade e o controle necessários ao ato decisório, desviando, de maneira mais palpável, da subjetividade.

Em um primeiro momento, antes de se adentrar nos critérios decisórios propriamente, há que se analisar algumas considerações erigidas por Castanheira acerca dos limites da juridicidade, asseverando ele não ser seguro acreditar que tenha a lei a capacidade de antever todos os casos, regulando-os exaustivamente, de modo que a experiência jurídica geral mostra que os concretos problemas jurídicos não são apenas os que o sistema jurídico positivo ou negativo prevê. Assim, conclui-se que não se pode identificar o direito como simplesmente o direito positivamente pressuposto ${ }^{7}$, ou seja, como as prescrições expressas ou não no seu corpus formal. Isso significa que o sistema jurídico não é pleno (sem lacunas) e não é fechado (autossuficiente), mas sim poroso e aberto, exigindo, portanto, uma contínua reintegração e reelaboração constitutiva por meio da dialética da sua realização histórica (NEVES, 1993, p. 210-212).

A partir de tal premissa, rompe o jurisprudencialismo com as ineficiências das soluções de cunho positivista até então apresentadas, uma vez que tendem a realizar a negação da autonomia normativamente constitutiva do julgador (negam esse poder criativo do julgador) ou reduzem a questão ao puro e simples problema de lacunas. Dessa maneira, como premissa a ser adotada, tem-se que compreender a existência de espaços livres de direito (religião, arte, ciência etc.) que com o direito se confrontam e estão em concreta dialética. É um espaço livre do direito que o direito positivo não define, tampouco exclui. A partir dessa ideia, pode-se admitir a possibilidade da existência de casos para os quais o direito positivo e o sistema jurídico não têm resposta, ou seja, não apresentam um critério normativo-jurídico aplicável, gerando, portanto, uma decisão que se constrói normativamente autônoma, ou, dito de outra forma, gerando uma decisão que se constrói de modo separado da normatividade (NEVES, 1993, p. 211).

O reconhecimento de tal situação mostra-se de grande valia em uma ambiência como a brasileira (de modernidade tardia), na qual, por meio de uma mixagem de teorias absorvidas de maneira acrítica e descontextualizada, conforme já explicitado anteriormente, realiza o Judiciário a implementação de uma série de direitos, que se impuseram nesse contexto pós 1988, bem como soluciona questões que não se encontram claras ou não apresentam resposta (os ditos casos difíceis), utilizando-se, muitas vezes, de uma miscelânea de princípios que são articulados e, até mesmo, criados - não se esquecendo do já mencionado "princípio" da ponderação como forma de fundamentar decisões que, em última análise, refletem apenas um entendimento subjetivo do julgador.

\footnotetext{
${ }^{7}$ Nesse sentido, explica o autor que “[...] a experiência jurídica tornou evidente e toda a problemática das lacunas corrobora que os casos jurídicos, não são apenas os que o sistema constituído positiva ou negativamente prevê, que a ausência de previsão não significa normativo-juridicamente mais do que isso mesmo - que o direito positivo constituído os não intencionou e, portanto, os não ponderou ou tomou posição sobre eles - tendo, já por essa razão, de se procurar as soluções jurídicas desses casos não previstos para além do direito positivamente pressuposto[...]”(NEVES, 1993, p. 212).
} 
Diante disso, a questão trazida pelo autor refere-se à forma como deve orientar-se o julgador diante de uma atividade criadora não orientada pela lei (NEVES, 1993, p. 218). Chega-se, neste momento, ao ponto chave deste texto, pois é a partir da resposta a essa pergunta que o jurisprudencialismo apresenta uma teoria que confere racionalidade ao ato decisório do julgador. Explica Castanheira Neves que o que se apresenta é um objetivo metodológico-normativo, o qual visa mostrar de que modo as novas criações dos juízes (direito dos juízes), as quais não podem ser obtidas da lei propriamente, são suscetíveis de embasarem-se em uma fundamentação calcada no direito, mantendo uma pretensão de validade:

A questão que nos interessa é saber como se pode e deve orientar o juiz numa tal actividade criadora do direito já não dirigida através da lei. $\mathrm{O}$ objetivo de nossa investigação não é jurídico-sociológico; não se propõe mostrar que factores causais operam efetivamente sobre a jurisprudência, o seu objetivo é metodológico e normativo: propõe-se mostrar de que modo as novas criações do direito-dos-juízes, que não podem ser obtidos só da lei, são susceptíveis de fundamentar-se em termos de direito e com pretensão de validade que a este é própria (NEVES, 1993, p. 218).

Antes de se buscar a resposta à sobredita pergunta, há que se entender como se dá a ideia de realização prática do direito, uma vez que Castanheira Neves entende existir duas dimensões distintas, sendo a primeira delas a intencionalidade normativa do direito, que configuraria o chamado "sistema"; e a segunda, a intencionalidade problemática do caso concreto, chamado de "problema". Desse modo, o problema prático sempre será apresentado como uma pergunta-intenção (no âmbito do problema) e a resposta sempre será encontrada a partir de uma resposta-intenção normativa do direito (no âmbito do sistema). Tem-se, dessa maneira, uma decisão calcada na correlação entre pergunta-intenção e resposta-intenção, realizando, dessa forma, a mediação entre sistema e problema. Assim, a decisão não é mais mera aplicação do direito, mas sim o momento de realização prática do direito (SIMIONI, 2014, p. 414).

Consegue-se com isso uma superação da concepção positivista clássica de análise sintática dos textos, indo-se para além da simples subsunção, bem como se transcende ao neopositivismo e sua análise semântica do sentido das normas que busca escolher, dentre as opções possíveis na moldura, a solução jurídica que irá prevalecer. Salienta-se ainda que, ao realizar a mediação entre sistema e problema por essa nova metodologia, não se vale o jurisprudencialismo apenas de normas jurídicas postas, mas também de todos os princípios e critérios fundamentais; no entanto, o apego ao texto positivo não foi totalmente abandonado para não se retroceder a uma fundamentação mística ou vaga da decisão, como ocorre no jusnaturalismo. Vê-se essa inclusão de princípios transpositivos como a garantia de que a decisão não será reduzida a uma articulação subjuntiva com base em textos legais positivados, fato este que abriria caminho para a discricionariedade do julgador (SIMIONI, 2014, p. 416).

Há ainda que se tratar da visão do autor acerca da questão da interpretação e da aplicação, uma vez que, para ele, o ato de interpretar já é a realização prática do direito, pois a interpretação não se consubstancia na 
simples busca da explicitação sintática ou semântica do que o legislador escreveu, sendo ela uma extração do critério normativo exigido para a solução do problema; não havendo, portanto, cisão entre norma e interpretação. Isso se dá, porque a norma é aquilo que se interpreta e pronto (não tem ela sentido antes da interpretação, ou, dito de outra forma, a norma não tem sentido em si). Também não se verifica cisão entre interpretação e aplicação, pois não há interpretação desvinculada de seu contexto prático de aplicação, uma vez que esta somente determina o sentido prático das normas por meio da resolução de problemas jurídicos concretos. Assim, a mediação entre sistema e problema ocorre por meio de uma interpretação que parte do caso concreto, diferentemente das concepções positivas e neopositivas, que partem dos textos de lei (SIMIONI, 2014, p. 431-432).

Uma vez apresentada, de maneira bastante sintética, a forma como se dá a realização prática do direito, passa-se agora à forma como se portará o julgador diante de uma situação, na qual terá ele de decidir sem a base legal estabelecida, ou seja, terá ele de realizar a mediação entre sistema e problema sem a presença da norma. Neste ponto que se verifica a solução necessária ao emprego de uma racionalidade para orientar o julgador, que, no caso brasileiro, vale-se das mixagens teóricas e construções que nada mais fazem que encobrir uma posição ativista, na qual prevalece apenas a sua subjetividade.

Conforme já visto, a realização prática do direito ocorre por meio da decisão, sendo que das normas extrai-se a intencionalidade normativa do direito e, por meio da interpretação, extrai-se o critério da norma. Mas, como já dito, a interpretação objetivada pelo jurisprudencialismo é diversa da interpretação convencional; assim, o critério por meio dela obtido não é um critério em abstrato como se comumente teria, mas serão sim critérios obtidos a partir do horizonte do problema prático (critérios com base no caso concreto). Cumpre salientar que funcionará o critério como o elemento que traça a distinção (certo x errado; lícito x ilícito e etc.), mas todo critério tem algo que o fundamenta, ou seja, aquilo que justifica a existência do critério; tal fundamento advirá do próprio corpo positivo ou dos princípios. No entanto, se não houver norma capaz de estabelecer o critério e o fundamento para compor o sistema na mediação entre sistema e problema terá a decisão de construir essa norma, criando o direito de modo autônomo (SIMIONI, 2014, p. 434).

Mas a ausência de um sistema normativo prévio não significa uma carta branca ao julgador para criar o critério e o fundamento que será usado para decidir, pois o sistema normativo não se esgota na norma positivada, existindo, portanto, critérios normativos transpositivos. Neste ponto, verifica-se a grande contribuição do jurisprudencialismo, pois deve a decisão respeitar tais critérios, restringindo a ação do subjetivismo do julgador, devendo ele buscar uma intencionalidade normativa do direito como um todo (SIMIONI, 2014, p. 462).

Passando-se ao método propriamente, deve o julgador, em um primeiro momento, identificar o problema prático, ou seja, a pergunta que o problema faz ao direito (pergunta-intenção); depois, em um segundo passo, tem que encontrar a intencionalidade normativa do direito para responder à pergunta-intenção 
identificada. Isso significa encontrar a resposta-intenção normativa do direito, perfazendo-se a mediação sistema e problema. Mas, diante da ausência da base legal, traz o jurisprudencialismo três condições que permitem ao julgador estabelecer a intencionalidade normativa, fugindo-se, assim, do subjetivismo (SIMIONI, 2014, p. 462 463), quais sejam: condição mundano-social, condição humana-existencial e condição ética.

É a partir dessas três condições que emergirá o direito que o juiz utilizará para a sua decisão, assim, faz-se necessário uma breve abordagem de cada uma delas. A condição mundano-social vê a socialidade como uma decorrência da condição humana, impondo a ideia de que o homem só existe como homem coexistindo com outros em sociedade, sendo o mundo o meio para essa existência. Mas essa coexistência precisa, por óbvio, de normas, sendo as normas jurídicas o regramento que vale de pessoa para pessoa independentemente das convicções particulares. Diante disso, é a condição mundano-social a primeira condição que justifica a emergência do direito, podendo ela ser encontrada na cultura, na natureza e na sociedade em geral (SIMIONI, 2014, p. 463).

Uma condição mundano-social - a dizer-nos que a primeira condição de exigência e constituição do direito se manifesta pela pluralidade humana na unicidade do mundo, mundo único (embora a considerar todos os "mundos", natural, social e cultural) que comungamos e partilhamos através de relações de um certo tipo situacional-comunicativo e justamente pela mediação desse mundo (em referência a ele e nos modos por ele possibilitados), as relações sociais (NEVES, 1993, p. 231).

Passando-se à condição humana-existencial, verifica-se, a partir dela, que viver como homem significa existir como um ser que se distancia do mundo e de si próprio para ultrapassar tanto o mundo, quanto a si próprio. Assim, o "ser" do humano é o "poder-ser". Mas isso deve ser pensado em interação com a primeira condição: uma vez que o homem só existe coexistindo (condição mundano-social) e ele é um "poder-ser" (condição humanaexistêncial), a síntese de tudo isso apresenta a ideia de que o homem é um "poder-ser com os outros". Tal conceito irá se manifestar materialmente na ideia de comunidade, sendo encontrada nas formas de integração institucional ou de ordem social (SIMIONI, 2014, p. 464).

Por fim, determina a derradeira condição de emergência do direito, condição ética, que para a integração comunitária (que no raciocínio até agora feito significa a integração de cada "poder ser com os outros") é essencial que se tenha uma coexistência baseada em normas éticas, pois o "poder-ser com os outros" exige também um "dever" de respeito com os outros e com a própria comunidade. Isso se torna importante, pois, se a comunidade é algo essencial para o humano (pois ele só existe coexistindo), a responsabilidade ética será a condição de validade dessa comunidade:

Condição cujo reconhecimento é verdadeiramente especificante do direito como direito, a postular que nas mundanais relações sociais e na ordem que dê critério a essas relações pela solução de problemas humanos da necessidade de integração comunitária se reconheça a cada homem a dignidade de sujeito ético, a dignidade de pessoa, e assim simultaneamente com um valor indispensável para o poder e a preponderância dos outros e comunitariamente responsabilizado (corresponsável e solidário) para com os outros - só assim ele poderá ser também simultaneamente titular de direitos (dirigidos aos outros) e de obrigações (exigidas pelos outros), em todos os níveis, segundo todos os princípios e em vol.09, nº 01, Rio de Janeiro, 2016. pp. 122-139 
todas as modalidades estruturais que normativamente se têm objectivado a constituírem o direito (o direito como específica realidade objetivo-cultural) (NEVES, 1993, p. 231).

Assim, por meio das três condições, a decisão jurídica encontraria um objeto problemático (uma relação social verdadeiramente prática) e um particular contexto problemático (contexto cultural, político, econômico etc.), sendo justamente deste contexto que se extrairia a resposta-intenção normativa do direito (sistema) (SIMIONI, 2014, p. 464).

Pode-se, porém, encontrar um problema nessa sistemática das três condições de emergência do direito, pois, como se percebe, são elas critérios ainda muito vagos para operacionalizar a decisão jurídica em termos práticos, uma vez que representam, em última análise, fundamentos da própria existência do direito, não garantindo sozinhas a racionalidade necessária à decisão. Justamente por isso, Castanheira Neves vale-se da analogia ${ }^{8}$ como critério e da consciência comunitária dos valores e princípios do direito ou simplesmente consciência jurídica geral como fundamento (SIMIONI, 2014, p. 466).

Começando pela consciência jurídica geral (fundamento), esta se constitui em uma objetificação histórico-comunitária do princípio normativo do direito, sendo a síntese, em uma determinada comunidade, de todos os princípios e valores que a determinam, ou seja, a síntese axiológico-jurídica de uma comunidade (SIMIONI, 2014, p. 470). Tal consciência jurídica geral constitui-se de uma experiência jurídica prática, a qual pode ser encontrada no âmbito institucional, citando-se os tribunais e as universidades e no âmbito cultural em que o enfoque é o próprio homem em si. Há que se salientar que seja em relação à jurisprudência dos tribunais seja em relação à produção doutrinária das universidades, só serão manifestações jurídicas da consciência jurídica geral, caso assumam o compromisso metodológico de realização do direito (SIMIONI, 2014, p. 472).

Em relação à analogia (critério), há alguns detalhes a serem destacados, sendo que sua escolha se deu por possibilitar a análise acerca daquilo que as coisas comparadas têm em comum e o que elas têm de diferente, possibilitando aproximar domínios diversos. Mas, para além disso, sua grande característica cinge-se ao fato de não possuir a analogia um controle lógico/empírico, sendo uma operação muito mais intuitiva, o que implica dizer que ela não possui uma base lógica, mas sim metalógica. No entanto, há que se advertir que não adota o jurisprudencialismo a tradicional comparação entre semelhanças dos textos legais e suas finalidades/objetivos/intenções, ou seja, analogia legis ${ }^{9}$, mas sim uma comparação no âmbito do caso concreto, leva-se em consideração a situação prática do problema (SIMIONI, 2014, p. 467).

\footnotetext{
${ }^{8}$ Importante salientar que Castanheira Neves, ao empregar a analogia como critério, não a utiliza em suas tradicionais concepções, quais sejam analogia legis e analogia iuris. A distinção principal adotada pelo autor cinge-se ao objeto da analogia, contudo isso será melhor elucidado no decorrer do texto.

${ }^{9}$ A analogia legis apoia-se em uma regra existente, aplicável à hipótese semelhante, de modo a encontrar a solução nos próprios repositórios legais (MAXIMILIANO, 2011, p. 171-172.), tratando-se, portanto, de uma comparação entre semelhanças dos textos legais e suas finalidades/objetivos/intenções. Há que se salientar que não se trata também da analogia iuris, uma vez que entende Castanheira Neves, ser a esta distinta da analogia legis apenas por uma diferença de grau, não havendo uma cisão qualitativa entre elas. Há em ambos os casos uma essencial identidade metodológica (NEVES, 1993, p. 258).
} 
Tem-se, desse modo, que a analogia legis ${ }^{I O}$ padece de dois problemas capitais que atingem a sua própria validade, impedindo-a de ser utilizada como critério, segundo Castanheira Neves. O primeiro problema refere-se ao fato de a estrutura da analogia postular uma relação entre particular-particular ou semelhante-semelhante, contudo o que se emprega em tal caso é uma lógica diversa, na qual se tem uma relação de subsunção conceitualcategorial, tem-se um juízo analítico-dedutivo do geral para o particular, quando se deveria ter um juízo sintéticoconstrutivo (argumentativo) numa conexão concreta sem mudanças de níveis. A relação deveria se dar entre casos concretos e não em uma lógica subsuntiva em que se caminha para uma comparação entre semelhanças dos textos legais e suas finalidades/objetivos/intenções. Já o segundo problema encontra-se na metodologia-jurídica, de modo que tal emprego da analogia continua a ser expressão do racionalismo sistemático-dedutivo, sendo seu critério e seu juízo um exemplo eloquente do método da inversão (NEVES, 1993, p. 258-259).

Levando em conta que é analogia uma operação mais intuitiva que dedutiva, pressuporá a sua aplicação três elementos acerca dos quais se pormenorizará as características. O primeiro deles trata-se do objeto. Como já asseverado, exige-se que a analogia ocorra entre casos jurídicos concretos e não entre textos legais, de modo que deve a analogia estar no problema, pois é nele que se encontrará a intencionalidade problemática que conduz a solução jurídica (SIMIONI, 2014, p. 467). Assim, aduz Castanheira Neves que:

"Os casos relevantes (caso-meta e caso-foro) serão juridicamente análogos quando seus respectivos e concretos sentidos problemático-jurídicos [...] se puderem pensar numa conexão justificada pela intenção fundamental de juridicidade que os constitui na sua especificidade jurídica" (NEVES, 1993, p. 258-259).

Passando-se ao segundo elemento, tem-se que a analogia deverá apresentar um fundamento, pois é ela intuitiva e não lógica, de modo que deverá apresentar um fundamento para justificar a correspondência que aponta as semelhanças e as diferenças entre os objetos. O fundamento analógico não poder ser a lógica, pois, conforme já dito, não pode deduzir/induzir uma identidade simplesmente por semelhança. É preciso justificar esse juízo analítico com base em fundamentos práticos-normativos, como valores éticos e princípios morais. Assim, será necessária uma argumentação prática coerente com a intencionalidade problemática (problema) e com a intencionalidade normativa (sistema) (SIMIONI, 2014, p. 467).

Uma ponderação comparativa a nível judicativo poderá levar a concluir que a solução jurídica do caso-foro é normativo-juridicamente adequada também para o caso-tema, no sentido estrito de satisfazer as expectativas normativo-jurídicas da sua solução [...] suscitadas no quadro da intencionalidade à juridicidade em geral, mas em referência pragmática à sua situação problemática. (NEVES, 1993, p. 258-259).

Importante salientar, conforme aduz Rafael Lazzarotto Simioni, que entre os neopositivistas havia uma insegurança no que concerne à fundamentação da analogia, uma vez que esta ocorria com base na comparação entre a solução jurídica da lei positiva e um sentimento subjetivo de justiça. No entanto, para Castanheira Neves esse sentimento de justiça advém da investigação da intencionalidade normativa do direito e não do julgador.

${ }^{10}$ Os problemas delineados no texto também se circunscrevem à analogia iuris. 
Tampouco é possível dizer que no âmbito do jurisprudencialismo ter-se-ia uma fundamentação metafísica ou suprapositiva para a analogia. A sua origem encontra-se sim na exigência prática de mediação entre sistema e problema do direito, mas o direito visto como um todo, lembrando-se que a validade do direito não está reduzida a sua positividade formal (SIMIONI, 2014, p. 468).

Por fim, o terceiro elemento a se destacar refere-se à validade jurídica que justifica esse o critério analógico adotado, de modo que essa validada embasa-se no princípio da igualdade. Assim, o juízo analógico abandona um condão voluntarista, bem como racionalista, para firmar-se em um juízo analítico normativo, fundado em valores e princípios caros a comunidade política. Dessa maneira, se o caso concreto (problema) apresenta a mesma pergunta-intenção para o direito (sistema) que outros casos similares, a analogia será correta. (SIMIONI, 2014, p. 468).

Diante de todo o exposto, verifica-se que o jurisprudencialismo de António Castanheira Neves, ao se construir partindo de uma compreensão hermenêutica, mas aliando a ela a fórmula de uma metodologia, mostrase como um profícuo caminho para se imprimir maior racionalidade às decisões em que não se tem o arcabouço positivo como respaldo, afastando-se, assim, os perigos afetos à discricionariedade judicial. Diante disso, tal teoria mostra-se de significativa importância no contexto brasileiro que, como bem aponta a crítica hermenêutica do direito, construiu-se em um cenário de mixagens e absorções acríticas de teorias, as quais são aplicadas de maneira desnaturada, proporcionando maior incentivo a uma postura ativista que, em última análise, acaba por confiar decisões de maior complexidade e afetas à implementação de direitos à subjetividade do juiz.

\section{CONCLUSÃO}

Teve o presente trabalho por escopo, a partir de um contexto pós-positivista, traçar uma investigação acerca da discricionariedade judicial e a necessidade de construção de uma racionalidade decisória como forma de afastar a subjetividade do julgador. Para tanto, ante a base hermenêutica que flerta tanto com Lenio Luiz Streck como com António Castanheira Neves, valeu-se o texto de elementos presentes na teoria de ambos os autores para o estudo da questão.

Assim, foi possível construir, com base nos contributos da crítica hermenêutica do direito, o panorama acerca do problema da discricionariedade do julgador e do ativismo judicial, tendo ela mostrado que o constitucionalismo do pós-guerra trouxe uma sobrevalorização do Judiciário, situação esta que começou a afetar o Brasil no período pós Constituição de 1988. Viu-se, assim, o cenário jurídico brasileiro ser inundado por teorias estrangeiras que, absorvidas de modo acrítico e descontextualizado, acabaram por fomentar uma perigosa aposta no arbítrio do juiz, notadamente quando este se põe diante de situações em que os limites legais não são claros para conduzir à atividade decisória, descambando-se para uma decisão calcada no subjetivismo. 
Valendo-se o texto da perspectiva de Lenio Luiz Streck e os desafios que coloca a serem superados pelo que ele denomina de Constitucionalismo Contemporâneo, foi possível estabelecer a atual situação do contexto brasileiro, no entanto, diante da operacionalidade e da aplicabilidade prática trazida pelo jurisprudencialismo, decorrentes de sua capacidade de associar hermenêutica e método, com vistas a propiciar maior racionalidade ao ato decisório e afastar a subjetividade, valeu-se o texto da teoria de António Castanheira Neves como o caminho mais profícuo para o enfrentamento da questão.

Espera-se que os argumentos esposados contribuam para incrementar a análise crítica acerca da postura do Judiciário e da busca pelo estabelecimento de uma maior racionalidade em atos decisórios de maior complexidade, bem como aos afetos à implementação de direitos, especialmente no contexto brasileiro.

\title{
FROM LENIO STRECK'S CRITICAL HERMENEUTICS OF LAW TO CASTANHEIRA NEVES' CASE LAW: A WAY TO GET OVER THE JUDICIAL DISCRETION IN CURRENT BRAZILIAN LEGAL REALITY
}

\begin{abstract}
Intend this paper, analysing the judicial discretion question, for this intention, it will be done in the post positivist context and will do a dialogue between Lenio Luiz Streck's critical hermeneutics of law and the António Castanheira Neves' case law, because both of writers have a hermeneutic's base. For that, the paper will show a panorama about of judicial discretion question in Brazil, using for this the critical hermeneutics of law that alert for acritc and decontextualized receptions of foreign theories. That theories created an environment that bet on the figure of the judge and his subjectivity for solution of complex issues and implementation of rights when the law dont show the way to decision. In this scenario, use this paper use the Castanheira Neves' case law for to give a rationale for the decision-making act. This theory was adopted because it can joining hermeneutics and method, providing greater practical applicability.
\end{abstract}

Keywords: Judicial Discretion; Case Law; Critical Hermeneutics of Law; Method; Operative Rationality

\section{REFERENCIAS BIBLIOGRÁFICAS}

ALEXY, Robert. Teoria dos Direitos Fundamentais. Trad. Virgílio Afonso da Silva. $5^{a}$ ed. São Paulo: Malheiros, 2006.

COSTA, Rafael de Oliveira. Hermenêutica Constitucional e Hermenêutica Filosófica: Horizontes da Previsibilidade das Decisões Judiciais. Revista Direito, Estado e Sociedade, no 44, p. 122-141, jan/jun. 2014. Disponível em < http://www.jur.puc-rio.br/revistades/index. php/revistades/article/view/382/343>. Acesso em: 7 out. 2015. 
DWORKIN, Ronald. Levando os Direitos a Sério. Trad. Nelson Boeira. 2a ed. São Paulo: Martins Fontes, 2007.

KELSEN, Hans. Teoria Pura do Direito. 6a ed. 3a Tiragem. Trad. João Baptista Machado. São Paulo: Martins Fontes, 1999.

MAXIMILIANO, Carlos. Hermenêutica e Aplicação do Direito, 20a ed. São Paulo: Forense, 2011.

MORAIS, José Luis Bolzan de; STRECK, Lenio Luiz. Ciência política e teoria do estado. 6. ed. Porto Alegre: Livraria do Advogado, 2008.

NEVES, António Castanheira. Metodologia Jurídica: problemas fundamentais. Coimbra: Coimbra Editora, 1993.

OLIVEIRA, Fabio Correa de. Morte e Vida da Constituição Dirigente. Rio de Janeiro: Lumen Iures, 2010.

SIMIONI, Rafael Lazzarotto. Curso de Hermenêutica Jurídica Contemporânea: do positivismo clássico ao póspositivismo jurídico. Curitiba: Juruá, 2014.

STRECK, Lenio Luiz. Jurisdição Constitucional e Hermenêutica: perspectivas e possibilidades de concretização dos direitos fundamentais - sociais no Brasil. Revista Novos Estudos Jurídicos, v. 8 no 2 p.257-301, maio/ago. 2003. Disponível em < http:// www6.univali.br/seer/index.php/nej/article/view/336/280>. Acesso em: 18 fev. 2015.

STRECK, Lenio Luiz. Verdade e Consenso: constituição, hermenêutica e teorias discursivas. $4^{a}$ ed. São Paulo: Saraiva, 2011.

TASSINARI, Clarissa. Jurisdição e ativismo judicial: limites da atuação do Judiciário. Porto Alegre: Livraria do Advogado, 2013.

Trabalho enviado em 16 de agosto de 2015.

Aceito em 10 de outubro de 2015. 